\title{
Product Delivery Expectations: Hanford LAW Product Performance and Acceptance Tanks Focus Area Task
}

by

E. W. Holtzscheiter

Westinghouse Savannah River Company

Savannah River Site

Aiken, South Carolina 29808

DOE Contract No. DE-AC09-96SR18500

This paper was prepared in connection with work done under the above contract number with the U.S. Department of Energy. By acceptance of this paper, the publisher and/or recipient acknowledges the U. S. Government's right to retain a nonexclusive, royalty-free license in and to any copyright covering this paper, along with the right to reproduce and to authorize others to reproduce all or part of the copyrighted paper. 


\section{DISCLAIMER}

This report was prepared as an account of work sponsored by an agency of the United States Government. Neither the United States Government nor any agency thereof, nor any of their employees, makes any warranty, express or implied, or assumes any legal liability or responsibility for the accuracy, completeness, or usefulness of any information, apparatus, product, or process disclosed, or represents that its use would not infringe privately owned rights. Reference herein to any specific commercial product, process, or service by trade name, trademark, manufacturer, or otherwise does not necessarily constitute or imply its endorsement, recommendation, or favoring by the United States Government or any agency chereof. The views and opinions of authors expressed herein do not necessarily state or reflect those of the United States Government or any agency thereof.

This report has been reproduced directly from the best available copy.

Available to DOE and DOE contractors from the Office of Scientific and Technical Information, P.O. Box 62, Oak Ridge, TN 37831; prices available from (615) 576-8401.

Available to the public from the National Technical Information Service, U.S. Department of Commerce, 5285 Port Royal Road, Springfield, VA 22161. 


\section{DISCLAIMER}

Portions of this document may be illegible in electronic image products. Images are produced from the best available original document. 
April 30, 1999

WSRC-RP-99-00341TL

Roger L. Gilchrist

Technology Integration Coordinator

Pacific Northwest national Laboratory

PO Box 999

Richland, Washington 99352

Dear Roger:

\section{PRODUCT DELIVERY EXPECTATIONS: HANFORD LAW PRODUCT PERFORMANCE AND ACCEPTANCE TANKS FOCUS AREA TASK (U)}

Attached is the letter report summarizing the Product Delivery Expectations for the Task, "Hanford LAW Product Performance and Acceptance". This summarizes an integrated technology development program aimed at addressing several key technology needs at the Hanford site.

Sincerely,

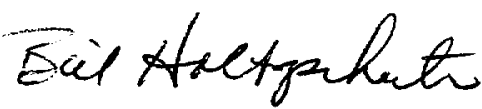

E. William Holtzscheiter Immobilization Technology Integration Manager Tanks Focus Area

\section{EWH/tyb}

cc: J. H. Westsik, PNNL

L. M. Papouchado, 773-A

F. M. Mann, PNNL N. R. Brown, DOE-RL J. M. Perez, Jr., PNNL L. S. Mamiya, DOE-RL

T. S. Gutmann, 704-S

E. A. Korzon, 703-A

J. D. Vienna, PNNL

J. R. Harbour, 773-43A

G. G. Wicks, 773-A
B. A. Carteret, PNNL

L. Roeder-Smith, PNNL

P. E. LaMont, DOE-RL

L. K. Holton, Jr., DOE-RL

T. P. Pietrok, DOE-RL

J. P. Morin, 703-H

S. J. Robinson, 703-A

T. M. Brouns, PNNL

D. K. Peeler, 773-43A

J. C. George, 773-43A

C. M. Jantzen, 773-A 
WSRC-RP-99-0034

April 30, 1999

TANKS FOCUS AREA

\section{PRODUCT DELIVERY EXPECTATIONS}

HANFORD LOW ACTIVITY WASTE PRODUCT ACCEPTANCE

E. W. Holtzscheiter

Technology Integration Manager

Immobilization

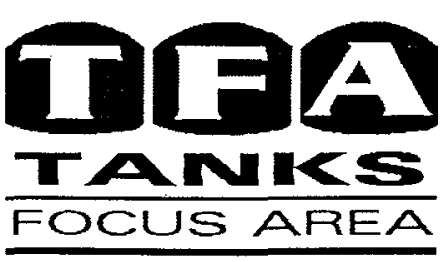




\section{PRODUCT DELIVERY EXPECTATIONS Hanford ILAW Product Acceptance Testing}

\section{Executive Summary}

The Hanford Site has been used to produce nuclear materials for the U.S. Department of Energy (DOE) and its predecessors. A large inventory of radioactive and mixed waste, largely generated during plutonium production, exists in 177 underground single- and double-shell tanks. These wastes are to be retrieved and separated into immobilized low-activity waste (ILAW) and high-level waste (HLW) fractions. Per the TriParty Agreement (1994), both the ILAW and HLW will be vitrified. It has been estimated that vitrification of the ILAW waste will result in over 500,000 metric tons or $200,000 \mathrm{~m}^{3}$ of ILAW glass. The DOE will deliver these wastes to private contractors for treatment and immobilization and will receive the products (immobilized waste) for storage and ultimate disposal. The ILAW glass is to be disposed in an on-site near-surface burial facility.

It must be demonstrated that the disposal system will adequately retain the radionuclides and prevent contamination of the surrounding environment. Waste form performance is the first line of defense against releases of contaminants after disposal and an integral part of the multiple engineered barrier system (EBS). Mann et al. (1998) found that the release of radionuclides from the waste form via interaction/reaction with water is the prime threat to the environment surrounding the disposal site. The two major dose contributors in Hanford ILAW glass that must be retained are ${ }^{99} \mathrm{Tc}$ and ${ }^{79} \mathrm{Se}$.

McGrail et al. (1998) describe the strategy for testing and modeling to determine/assess the radionuclide release rates from ILAW glass. This strategy requires extensive, time consuming testing and modeling for each glass considered. The Department of Energy must be able to assess the validity of a glass proposed by the vendor in a response time on the order of three months. The Tanks Focus Area (TFA) Immobilization Program has outlined a task to reduce the Department of Energy's risk of accepting an ILAW glass in a reasonable response time. The task will evaluate key tests, relate the results to the Performance Assessment (PA) modeling effort, and develop an Acceptable Glass Composition Region with a high confidence of acceptable long-term glass performance. This will allow the Department of Energy to accept a defined range of compositions and only have to invoke further analysis on glasses near the boundary of the acceptability region. The task is integrated with and complementary to the Performance Assessment task described by McGrail et al. (1998).

In the TFA task, the long-term performance of glasses will be screened as a function of glass composition, which can ultimately be described as an acceptable glass composition region (AGCR). Composition was chosen since it is directly measurable in a production plant and in experimentation. To support consistent measurement of composition, the initial work in this technical area was to develop an analytical test standard to verify the quality of the chemical analyses performed on ILAW glasses and to ensure the qualifications of analytical laboratories. In FY98 Argonne National Laboratory developed an ILAW nonradioactive formulation and will complete round robin analysis which will be fully documented by the end of FY99. This glass will be included in the test matrices for glasses evaluated in this task.

The experimentation strategy has been reviewed and endorsed by an expert panel of glass scientists (Attachment 1- Table I); their recommendations have been incorporated. Follow-up with the panel is planned at each significant data delivery point in the task. The data deliveries will support Performance Assessment data calls in FYO0 and FY01.

The key elements of the Product Acceptance Task are:

A. Development and Analysis of the ILAW Analytical Test Standard - LRM Glass.

The foundation for prediction of glass performance via composition relationships is good glass analytical chemistry data. To ensure that both the data and the laboratories analyzing the glasses meet 
the required performance standard, a Low Activity Glass (LRM) was formulated by ANL to approximate the expected composite of glasses to be made at Hanford. This glass has also been compared to ILAW formulations relevant to Oak Ridge and to those tested in conjunction with the Mixed Waste Focus Area glasses demonstrated in the Transportable Vitrification System (TVS). A thorough analysis was performed by ANL and reported in FY98 (S. F. Wolf, W. L. Ebert,et al (1998)) with the results of the round robin tests expected to be completed in FY99. Once complete, this glass is available to benchmark analytical results.

B. Independent Review of the Test Strategy Described in the Performance Assessment This activity enlisted the support of several international experts in glass science and modeling to review the Hanford ILAW strategy document. The panel members are independent of the work underway at Pacific Northwest National Laboratory (PNNL), but have extensive experience in the glass formulation and modeling of glass performance. This review will be completed and consolidated by Dr. George Wicks in the last quarter of FY99. Preliminary results have been communicated to Hanford and updates will continue as information from the panel becomes available. The members of the review panel are shown in Attachment 1 - Table II.

C. Review of the International Long Term Burial Program Results.

This activity was subcontracted to Dr. Dave Clark, the University of Florida, Gainsville, FL since he has maintained continuity with this program and the results of the international tests. Dr. Clark is consolidating the available data and evaluating composition regions in terms of a ternary of glass formers, intermediates, and modifiers. This will provide additional insight into the compositional consistency of acceptable glasses.

D. Literature Survey and Evaluation of Test Techniques and Results.

There are many tests that have been used over the years to evaluate glasses, some tests have been taken through the independent review process of the ASTM (e.g. Product Consistency Test (PCT)), others are more suited to being used as glass research tools. The survey included available results from the tests that have been designated in the Hanford Performance Assessment Strategy. Some issues with inconsistency of data and differences in performance prediction between tests were observed in the literature. The insights from the data in the survey were applied to the Tanks Focus Area test plan to ensure that tests were included to address inconsistencies previously observed.

E. Develop an Integrated Test Plan that Incorporates the Key Tests in the Hanford Performance Assessment Strategy; Review the Test Protocols with a National Expert Panel; and Execute the Test Program.

The test strategy was developed and reviewed with the expert panel in December 1998 (listed in Attachment 1 - Table I). If recommendations from the independent review (Attachment 1- Table II) result in changes to the strategy, the test plan will be appropriately revised or expanded. During FY99, funding reductions in this task resulted in limiting the number of glasses to be tested to approximately half of those planned and in extension of the Phase 1 schedule for completion into FY00. If additional funding becomes available, the schedule can be accelerated. Glasses are currently being fabricated for testing using two of the four test protocols. The TFA will perform both Vapor Phase Hydration testing (VHT) and PCT-Methods A \& B as discussed in the test plan. PNNL under EM-30 is in the process of performing the PA modeling and the single pass and pressurized flow-through testing (the third and fourth protocols). The flow-through testing will be performed on a limited number of glasses triggered by results from VPH tests and PCTs.

Results from the VHT will give information about the alteration phases that are likely to form during the corrosion of glasses in very concentrated solutions. This test is also intended to give a "quick screen" of glasses that are expected to perform poorly in other, longer term, corrosion tests. The high surface to volume (S/V) PCT (referred to as PCT-B) results will describe the static corrosion behavior of glasses as a function of time. The data from these tests can be used directly to rank glass 
compositions for durability or can serve as validation for modeling of performance of glass as a function of time and composition. The 7-day PCT (referred to as PCT-A) will serve as the first data point in the long-term PCT-B map of corrosion behavior and will help to determine the appropriate times for sampling. This test will also serve as an important link between the measurements being performed in this study and the very large and growing database of glasses being tested with the PCTA method. Another area that will have to be linked is the relationship between bulk glass corrosion and actual release of the specific isotopes of interest $\left({ }^{99} \mathrm{Tc}\right.$ and $\left.{ }^{79} \mathrm{Se}\right)$. Some work is in progress at ANL in understanding the retention of these isotopes in the alteration phase boundary layers.

F. Analyze the Glass Results, Correlate with Theory, Analyze for Prediction Consistency, and Review the Results with the Expert Panel.

The glasses will be analyzed, alteration phases characterized, and results compared to similar glasses tested by different protocols. In addition, simulated natural analogs and other well-characterized glasses will be carried through the testing to provide a benchmark for evaluation. Once the glasses are evaluated and performance assessed, then selected glasses will be further tested and the performance assessed.

G. Resolve Issues with the Test Protocols, Test Results and Data Consistency.

Predictive testing for long term performance has been linked for credibility to geological analogs and long term burial tests. The nature of the Hanford testing requirements to support the numerous variations in waste feed composition and the fact that the waste is a high sodium waste does not lend itself to this traditional strategy. The use of predictive glass tests coupled with the performance assessment model, without relevant geological analogs is a departure from the precedents of the HLW program. Since this is breaking new ground, further testing is expected after the Phase I results are complete to achieve closure with the review team and glass theory.

H. Develop the Acceptable Glass Composition Region (AGCR)

Test glasses fabricated within a composition region consistent with the expected variability of the privatization vendor's production glasses with each of the validated test protocols. Determine and document the ACGR. The results from this activity provide a basis for the Department of Energy to evaluate candidate compositions provided by the privatization vendor. The AGCR can be used to guide decisions and minimize risks of accepting glasses with unacceptable long-term performance.

\section{Discussion of Kev Deliverables}

A. 1000 Pounds of ILAW Glass as an Analytical Test Standard: The glass will be well characterized through internal analytical evaluation at Argonne National Laboratory (ANL) and through a round robin chemical analyses documented by ANL. The glass will be used to qualify analytical laboratories in support of the Hanford ILAW vitrification and to support development programs supporting glass formulation.

B. Report Summarizing the Independent Review of the Performance Assessment Test Strategy: This report will document the comments and issues raised by the international review panel and their recommendations for resolving identified issues.

C. Literature Survey of Potential Long Term Predictive Test Techniques: The literature survey and evaluation of glass analysis techniques was completed in FY98 and provided a baseline evaluation of the techniques included in the Hanford strategy. The weaknesses and inconsistencies in the reported data were identified and will have to be resolved in the TFA tests. The evaluation results contributed to the Test Plan completed in FY 99.

D. Test Plan for Initial Compositional Envelope: A test plan was developed and reviewed with a panel of experts for input and modification. The test plan was issued in early FY99. The TFA test plan includes part of the tests (Vapor Phase Hydration and Product Consistency Tests-Methods A \& B) that make up the Hanford strategy. The plan integrates the Tanks Focus Area work with the work funded by Hanford and is co-authored by the principal investigators in both organizations. 
E. Glass Test Results-Phase I Documentation of the test results and evaluation of the glass response: This report will provide the initial results for glass long-term performance testing. These results will include testing up to a year for both PCT's and VHT's and correlation with predictions. Longer duration results will be reported as the required time has elapsed. When the results are complete, they will be reviewed by the expert panel (Attachment 1 - Table I) then the next phase of testing will be defined. Currently the funding reductions limit the ability of the team to provide sufficient information to impact the FYOO data call.

F. Final Glass Test Protocol and Results: Several iterations are expected to finalize the test protocols that will project long term performance of glass in disposal scenarios. This report will document the protocols, their tie to glass corrosion theory, and their performance in a typical ILAW composition region.

G. Acceptable Glass Composition Region (AGCR): Define and document an acceptable glass composition region for use by the Department of Energy in evaluating the expected long-term performance of ILAW glasses proposed by the privatization vendor. It is expected that glass compositions will have substantial variation required to accommodate the inherent variability in waste feed compositions.

\section{Product Requirements}

\section{Hanford Site}

A. Independent Review of the Hanford ILAW Disposal Facility Performance Assessment Test Strategy: A review that identifies areas that need to be strengthened or modified to provide a technically thorough and correct evaluation of the performance of the Immobilized Low Activity Waste form and the transport of key hazardous and radioactive constituents over the performance period ( 10,000 years).

B. A test protocol that will allow prediction of the leaching of key constituents over the performance period: A test or suite of tests that can be used to predict the leaching of ILAW glass in the disposal environment over the performance period of $(\sim 10,000$ years $)$. If the test is not a direct measurement, the approach to tying the raw results to theory must be developed and the basis for validation documented. The results from the test protocol will be used to provide glass performance parameters to the Performance Assessment Models and if possible, be used to evaluate the vendor provided glasses for performance.

C. Acceptable Glass Composition Region ( $A G C R$ ): Utilizing the tests developed to support the Performance Assessment, an acceptable composition region, will be identified for use by the Department of Energy to screen potential glass compositions provided by the vendor. The AGCR will provide insight that reduces the technical risk of accepting a composition well within the identified region, but as the glasses approach the edge of the AGCR, additional testing may be required. The validity of the AGCR will be related to well-characterized glasses, natural analogs and as possible, results from the international long-term burial program.

\section{Task/Product Review Strategy}

Technical review of the guiding documents and the test strategy has been integrated into the task. The Performance Assessment Test Strategy will be reviewed by an international team of well known glass experts (Attachment 1-Table II). The test strategy and results (initial and final) will be reviewed by a national team of glass scientists with experience in long term glass evaluation. This team will have multisite representation and the participation of the Tanks Focus Area Technical Advisory group (Attachment 1 - Table I). Standard reviews of the test plans and reports by the Technology Integration Manager and the users will also be performed. Since Savannah River has a strong interest in this task, key documents such as test plans and reports summarizing results and conclusions will be available to SRS for the same reviews provided to the Hanford users.

\section{$\underline{\text { Roles and Responsibilities }}$}


Argonne National Laboratory (ANL) developed and characterized the ILAW analytical test standard, ARM Glass (Bill Ebert). Pacific Northwest National Laboratory (PNNL) serves in two roles: (1) to provide the technical support to the development and documentation of the ILAW Disposal Facility Performance Assessment (Pete McGrail) and (2) as one of two principal investigators for the Tanks Focus Area task (John Vienna). Savannah River Technology Center (SRTC) provides the second principal Tanks Focus Area investigator (David Peeler) and consultation from key scientist that made major contributions in this technical area for the High Level Waste program (George Wicks and Carol Jantzen). By consolidating the team and utilizing key strengths from both sites, a unified approach may be developed that is consistent with the large technical basis supporting the HLW program. (Savannah River, due to the potential relationship of this task to the High Level Waste Program, has been identified as a site with strong interest in the results.) The technical planning is integrated with the efforts developed and supported by Hanford under the EM-30 program and are coordinated with Fred Mann and Phil LaMont.

\section{Summary}

This task has several facets all aimed at providing technical products that will support the immobilization of Hanford's Low Activity Waste. The current key technical products support the development of a technically sound Performance Assessment of the ILAW Disposal Facility and the development of a product acceptance specification for Phase 2 privatization that will reduce the risk of making a glass that will not meet the Performance Assessment requirements for long term stability. Both products require related glass formulation and development activities and must be coordinated with the overall EM-30 program supporting the development of the Performance Assessment. This integrated test matrix will provide key glass results from selected glass test protocols (VHT and PCT's A \&B) to be compared to flow-through testing supported by the EM-30 part of the strategy. The follow-on work will address areas of inconsistency and develop a way to resolve and to correlate with known theory. Once the test protocols are developed and validated, the approach will be used to provide an acceptable glass composition region for the Phase 2 specification. Since this task breaks new ground in developing predictive capability, a review process external to the technical team is critical for acceptance by the technical community and is key to Hanford's Performance Assessment review process.

\section{References}

Tri-Party Agreement, Washington State Department of Ecology, U.S. Environmental Protection Agency, and U.S. Department of Energy, Hanford Federal Facility Agreement and Consent Order, 89-10, Rev. 3, Fourth Amendment, Olympia, WA (1994)

B. P. McGrail, W. L. Ebert, D. H. Bacon, and D. M. Strachan, A Strategy to Conduct an Analysis of the Long-Term Performance of Low-Activity Waste Glass in a Shallow Subsurface Disposal System at Hanford, PNNL-11834, Pacific Northwest National Laboratory, Richland, WA (1998)

S. F. Wolf, W. L. Ebert, J. S. Luo, and D. M. Strachan, A Data Base and Standard Material for Use in Acceptance Testing of Low-Activity Waste Products, ANL-98/9, Argonne National Laboratory, Argonne, IL (1998)

F. M. Mann, R. J. Puish, P. D. Rittman, A. H. Lu, G. F. Williamson, N. R. Brown, P. E. LaMont, N. W. Kline, J. A. Voogd, Y. Chen, C. R. Eiholzer, C. T. Kincaid, and B. P. McGrail, Hanford Immobilized LowActivity Tank Waste Performance Assessment, DOE/RL-97-69, U.S. Department of Energy, Richland, WA (1998) 
WSRC-RP-99-0034 $!$

April 30, 1999

Page 7

Attachment 1:

\section{Expert Panel for Review of TFA Test Plans and Results}

The TFA Immobilization Program convened a panel of experts to discuss and decide upon an approach to developing an AGCR for the Hanford ILAW product (George and Harbour 1999). Those present at the meeting are listed in Table $I$, along with their affiliation and area of expertise. A consensus approach was identified for developing a composition region with a low risk of not meeting the performance goals of the Hanford burial site.

Table I. List of attendees at approach meeting

\begin{tabular}{ll}
\hline Name & Affiliation \\
\hline Prof. David Clark & Univ. of Florida \\
Prof. Patricia Dove & Georgia Tech. \\
Dr. Bill Ebert & ANL \\
Dr. John Harbour & WSRC \\
Dr. Bill Holtzscheiter & WSRC-TFA \\
Dr. Pavel Hrma & PNNL \\
Dr. Carol Jantzen & WSRC \\
Dr. B. Pete McGrail & PNNL \\
Dr. David Peeler & WSRC \\
Prof. Ian Pegg & CUA \\
Prof. Joe Simmons & Univ. of Florida \\
Dr. Gary Smith & PNNL \\
Dr. Denis Strachan & PNNL \\
Mr. John Vienna & PNNL \\
Dr. Thomas Weber & TFA -TAG \\
Dr. George Wicks & WSRC \\
Prof. Michael Weinberg & Univ. of Arizona \\
\hline
\end{tabular}

International Review Group for the Performance Assessment Test Strategy

The review panel was selected and requested to participate based on their international recognition in the fields of glass formulation, modeling and performance. Their participation is greatly appreciated by the Tanks Focus Area Technical Team.

Table II. List of scientists reviewing the Hanford PA strategy document

\begin{tabular}{ll}
\hline Name & Affiliation \\
\hline Dr. George Wicks & WSRC/SRTC-Coordinator \\
Dr. Bernd Grambow & Karlsruhe, Germany \\
Prof. Werner Lutze & University of New Mexico \\
Dr. Etienne Vernez & CEA/VALRHO \\
Dr. Elmer Wilhite & WSRC/SRTC \\
\hline
\end{tabular}


WSRC-RP-99-0034 I

April 30, 1999

Page 8

Hanford Low Activity Waste Product Performance and Acceptance $\begin{array}{lllll}\text { FY98 } & \text { FY99 } & \text { FY00 } & \text { FY01 } & \text { FY02 }\end{array}$

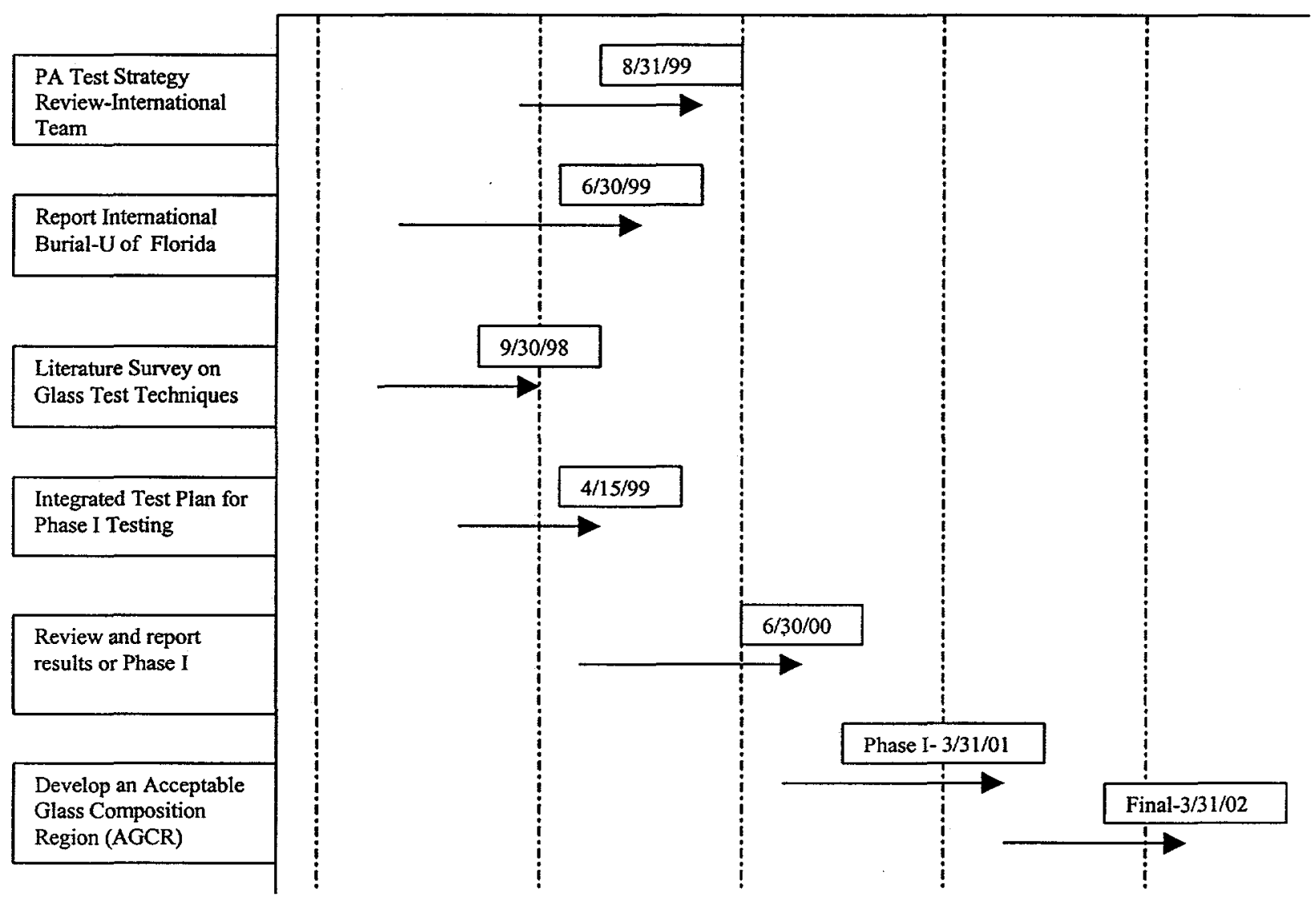

